\title{
HIV-related risk perception among female sex workers in Nigeria
}

This article was published in the following Dove Press journal:

HIVIAIDS - Research and Palliative Care

26 July $201 \mathrm{I}$

Number of times this article has been viewed

\section{Augustine Ankomah' \\ Godpower Omoregie' \\ Zacch Akinyemi ${ }^{2}$ \\ Jennifer Anyanti' \\ Olaronke Ladipo' \\ Samson Adebayo'}

'Society for Family Health, Abuja, Nigeria; ${ }^{2}$ Population Services International, Kigali, Rwanda
Correspondence: Augustine Ankomah Society for Family Health, 8 Port Harcourt Crescent, Garki, Area II, Abuja, Nigeria

Tel +2348082338720

Fax +234 946I 8823

Email aankomah@sfhnigeria.org
Background: Over one-third of sex workers in Nigeria are infected with human immunodeficiency virus (HIV), yet there is a lack of understanding of sex workers' own perception of sexual risk-taking. Applying the theory of cognitive dissonance, this paper examined the personal HIV risk perception of brothel-based sex workers.

Methods: The study is based on 24 focus group discussions held among brothel-based sex workers in four geographically and culturally dispersed cities in Nigeria.

Results: It was found that sex workers underestimated their risk of infection and rationalized, defended, or justified their behaviors, a typical psychological response to worry, threat, and anxiety arising from the apparent discrepancies between beliefs and behaviors. To reduce dissonance, many sex workers had a strong belief in fatalism, predestination, and faith-based invulnerability to HIV infection. Many believed that one will not die of acquired immune deficiency syndrome if it is not ordained by God. The sex workers also had a high level of HIV-related stigma.

Conclusion: From these findings, most sex workers considered risk reduction and in particular condom use as far beyond their control or even unnecessary, as a result of their strong beliefs in fatalism and predestination. Therefore, one critical area of intervention is the need to assist sex workers to develop accurate means of assessing their personal vulnerability and self-appraisal of HIV-related risk.

Keywords: female sex workers, cognitive dissonance, risk perception, risky behavior, focus group discussions, Nigeria

\section{Introduction}

While sex work is global, it is in sub-Saharan Africa that sex workers are at most risk of human immunodeficiency virus (HIV) infection and acquired immune deficiency syndrome (AIDS). ${ }^{1}$ The prevalence of sexually transmitted infections is very high among sex workers in Nigeria. ${ }^{2}$ Early HIV seroprevalence studies among sex workers showed that prevalence increased from $13.4 \%$ in $1991-1992$ to $36.4 \%$ in $1996 .{ }^{3}$ Notwithstanding increased funding for HIV prevention activities among sex workers in Nigeria since the 1990s, HIV prevalence among sex workers has remained high over the past decade. HIV prevalence among sex workers in 2007 was still over $30 \%$, and in some cities like Kano and Abuja, 50\% of all brothel-based sex workers are HIV-infected. ${ }^{4}$ Thus, while HIV prevalence among the general population in Nigeria has been declining from its peak of $5.8 \%$ in 2001 to $4.1 \%$ in $2011,{ }^{5}$ prevalence among brothel-based sex workers has shown no sign of declining.

Given this background, a priority for the growing HIV prevention programs in the country is the development and implementation of interventions to address HIV-related 
risk associated with brothel-based sex work. Although the population of brothel-based sex workers is very small in size compared with the general Nigeria population, a recent modeling of apportionment of new infections estimated that in some states (such as Ogun in south-west Nigeria and Benue in north-central Nigeria), sex workers and their clients account for about $18 \%$ of all new infections. ${ }^{6,7}$ As noted in the literature, interventions that prevent the transmission of HIV among those with the highest rate of partner change will achieve the greatest reduction in new HIV infections. ${ }^{8}$ Therefore, changing behaviors of sex workers and their clients is essential to reducing HIV transmission in Nigeria. While sex work in Nigeria remains illegal, it is commonplace, occurring in both residential brothels and at street corners in major cities. ${ }^{9-14}$

HIV prevalence among sex workers in Nigeria is very high, yet surveys report very low levels of HIV-related risk perception among this group. In a recent survey among mostat-risk populations in six states in Nigeria, over half of sex workers did not consider themselves at risk of HIV infection. ${ }^{4}$ In Lagos state, with the highest concentration of sex workers in Nigeria, only $16 \%$ of brothel-based sex workers felt they were at risk, even though each has on average 34 clients per week. ${ }^{4}$ Despite their high-risk sexual activity, many sex workers perceive their risk of HIV infection to be low. ${ }^{15}$ Given the overall high HIV prevalence among sex workers, why do most of them consider themselves not at risk?

One understudied area noted in the literature is the apparent lack of understanding of sex workers' own perception of unsafe sex, why they engage in unprotected sex, and how they understand personal sexual risk-taking. ${ }^{12,16}$ In an attempt to answer some of these questions, we examined the perception of risk among brothel-based sex workers by applying Festinger's cognitive dissonance theory ${ }^{17}$ and its variant, the principle of "balance theory." 18

Cognitive consistency theories have long postulated that disparities between beliefs and perceived behavior are discomforting and hence people strive to reduce dissonance. The balance theory argues that people feel more comfortable when they agree with issues they like and disagree with issues they dislike. ${ }^{17,18}$ Whenever there is a discrepancy between beliefs and behaviors, something must change in order to eliminate or reduce dissonance. The theory proposes that people have a motivational drive to reduce dissonance. This they do by changing their attitudes, beliefs, or actions. Dissonance may also be reduced by justifying, blaming, and denying.

Variants of this paradigm have been used in studying other most-at-risk populations. Bauman and Siege ${ }^{19}$ investigated defensive coping in a sample of gay men and found that men who denied or underestimated their risk of HIV infection experienced lower anxiety. We will apply this paradigm to explain why most sex workers engage in risky sexual behavior and yet do not consider themselves at risk of HIV infection. The study is intended to fill the gap of incorrect HIV self-appraisal of risk by exploring how sex workers in Nigeria perceive the risks of sex work and to understand their personal HIV risk assessment. We also explored the key strategies used by sex workers to reduce or minimize cognitive dissonance.

\section{Methods and materials}

This study is based on a total of 24 focus group discussions held with brothel-based sex workers in four Nigerian cities: Ibadan, Benin City, Jos, and Port Harcourt. Selection of brothels was purposive but brothels were stratified into "high-class" and "low-class" based on location. Six brothels were selected in each city, comprising two from the affluent areas (high-class) and four from the poorer residential areas (low-class). Selection of participants was through convenience sampling, whereby any sex worker on site who was willing to participate in the discussion was selected. Only four sex workers, two each in Jos and Port Harcourt, refused to participate when contacted. There were 8-12 participants per group and the discussions were conducted in the bar or any appropriate area within the premises.

Because sex work is illegal and respondents will not sign any consent form for fear of the law, we obtained verbal consent from each sex worker and also from each brothel management. Confidentiality was assured. Each group discussion lasted between 60 and 90 minutes. The medium of communication was mostly Pidgin English, except in Jos, where it was combined with Hausa (a widely spoken local language in northern Nigeria). The moderators were experienced researchers who have conducted similar focus groups in the past. Two females moderated the discussions in Port Harcourt and Jos while two men were in charge of Benin and Ibadan. The notetakers were all males who received prior training before the event. Notetakers also captured nonverbal responses and cues. Experience has shown in Nigeria that among sex workers, the gender of the moderators and other facilitators made no difference to the focus group discussions in terms of quality and quantity of information obtained. ${ }^{12}$

A common focus group guide which consisted of a set of topics to be discussed was developed by the research team (coauthors) and used by all moderators to ensure standardization as far as possible. Moderators were trained and 
ensured that every participant contributed to the discussions. During the discussion session, no one participant was allowed to dominate the discussions. The topics discussed included the following: awareness about HIV, the nature of sex work and sexual risk-taking, risk of HIV infection and personal risk appraisal, HIV risk reduction strategies, HIV prevention including condom negotiation, and HIV stigma and discrimination. To remove any possibility of bias in responses, no monetary incentives were offered. However, participants were given soft drinks and snacks in the course of the discussion as well as complimentary condoms and promotional items of little monetary value (such as keyrings, T-shirts) at the end of the discussion. They were given the opportunity to ask questions at the end of the discussions and many of the misconceptions about HIV they held were addressed. It is important to note that interactions following the focus group discussions were not included as part of the data used in this report.

The recorded tapes were later transcribed verbatim and then translated into English. The translated transcript of each focus group was read by at least three of the authors. Coding was done manually based on the theoretical paradigm, ie, cognitive dissonance. The codes, made up of keywords and phrases, were developed from the data. The codes were then "grouped together under higher order headings." 20 Consequently, on a higher logical level of abstraction we created codes, subcategories, categories, and themes. ${ }^{21} \mathrm{We}$ employed latent content analysis in the interpretation of data. Qualitative analysis may focus on manifest or latent content. ${ }^{21}$ Manifest analysis describes the visible and the obvious, while latent content analysis involves an interpretation of the underlying and inferred meaning of the text. ${ }^{21,22}$ Latent analysis allows for indepth interpretation and a systematic and thorough evaluation to assess for the presence or absence of a particular idea or theory. ${ }^{21,22}$ The research team met on various occasions to discuss the coding, analysis, and interpretation, and addressed discrepancies which required clarity. Representative quotes that best described the categories were agreed upon by the authors and selected, but in some instances contrasting minority opinions were also highlighted.

\section{Results}

\section{Characteristics of participants}

Participants in the study were female sex workers resident in brothels in the Port Harcourt, Benin, Ibadan, and Jos cities of Nigeria. The majority were Christians and single. The reported age ranged between 18 and 42 years, with the majority being in their twenties. This is in line with surveys that report the mean age of the Nigerian sex worker as being 27 years. ${ }^{4}$ Most of them had some secondary education, particularly those from Port Harcourt and Benin. The charge "per round of sex" varied, and depended on several indicators including level of sophistication, which could be based on whether it was a "high-class" or "low-class" brothel, or type of dress and general appearance. Sex workers who were young, better educated, and spoke good English charged more. Similarly, new arrivals to the brothel also charged a premium.

\section{Perceived risk of sexual transmission of HIV}

In spite of the evidence that nearly all new cases of adult HIV infection in Nigeria are sexually transmitted, most of the sex workers chose to emphasize that sex was not the only means of HIV transmission. Many of the women played down the sexual transmission aspect and drew attention to the other modes of transmission as a means of ensuring that their behavior was consistent with their beliefs. "I believe AIDS cannot only be contracted through [sex]. AIDS can be contracted through anything that has to do with blood. If you have gonorrhea and syphilis and you don't treat them, they can lead to something else. It's not only through [sex] that you get it! You can contract it through mosquito bites ... but for me I don't believe AIDS is only through sex ..."

\section{Risk generalization}

The participants knew of the severity of AIDS and mentioned that AIDS had no cure. A key strategy in reducing dissonance among the sex workers was through risk-leveling, ie, the strong belief that "everybody was at risk." It was clear from the discussions that sex workers were offended when they were considered as being at elevated risk of HIV infection. They rejected being treated with suspicion and ostracism as disease vectors or conduits for the spread of AIDS, especially by health care providers. The sex workers argued that the problem of AIDS was not confined to them, that it was everybody's problem, that HIV could and does affect "ordinary" people as well: "It is affecting everybody, it does not know rich, or poor; anybody can catch it." A participant emphasized: "It is also a problem of those who are married. It is a problem of young man, young woman, old man and old woman." Another participant who apparently knew someone who had died of AIDS emphasized: "You think that it's only Ashawo (local word for prostitute) that get AIDS. One woman died in ... (name of village withheld) of AIDS. She was a married woman." Some of them even felt their risk of 
infection was far lower than the general population, apparently because they have the opportunity to be educated about HIV preventive measures compared with other women who may never have heard about condoms. "Had it been I am not doing this business (sex work), I would not have known what condom is and how it is used. There are people staying in their private homes who don't know the meaning of condom and its importance."

\section{High levels of stigma against persons living with AIDS}

There was evidence of stigma and discrimination against persons living with AIDS. Many of the respondents held negative and stigmatizing views against people living with AIDS and nearly all wanted nothing to do with HIV and persons living with HIV and AIDS. They all admitted that dying from AIDS was particularly shameful. They were of the opinion that one should have very little to do with a person living with AIDS. One mentioned: "Why do you want to associate with such a person? Everybody will suspect you" (of also being HIV-positive). They cataloged the shame and embarrassment AIDS brings to a family in a community. A participant indicated: "All death is death but some death is bad. Maybe you have a brother or sister and a family, then you die from AIDS. It is a disgrace to the family. Here I am not sure all death is death. It is a big disgrace to the family as a whole." They exaggerated the symptoms of AIDS to support why a person should not be associated with anyone living with AIDS: "The disease will make you become slim. ... After you contract AIDS your placenta and your womb will start to disappear." In fact, a few even mentioned that anybody known to be carrying the virus should be quarantined. A respondent stated: "It's a bad disease ... the person be hospitalized indefinitely or removed from the community."

\section{Faith-based invulnerability to HIV infection}

For many of the sex workers, belief and trust in God were important attributes that offered safety and security from infection. The belief in the transcendental created some form of risk relief among sex workers. While they appreciated the contradiction that their religion may not support their work, many rationalized by drawing attention to the particular personal, familial problems, circumstances, or tragedies that caused them to choose sex work. This dependence on God was observed among sex workers, particularly in Ibadan and Jos, where most strongly believed that it was only God who can protect them from HIV infection: "Whether high or low risk, I put my trust in God ... it is only God that gives protection." In Ibadan, some brothels organize daily morning prayer sessions during which they asked God for divine protection and prayed that God would bless their work and protect them from contracting AIDS: "We pray that God will not allow anything bad, anything terrible to come near us." Another mentioned: "I will ask for God's protection since these things are from God. There was a case where the husband had AIDS and the wife does not though they have been having sex - so all these things are from God. ... I know that God being on my side I can never get infected."

One of the dangerous outcomes of relying on God for protection is the strong belief in faith-based invulnerability to HIV infection. Many were of the view that they will never get infected because of their faith: "I will not catch it in Jesus' name." There was also the misconception that condoms were irrelevant, since it is only God who can protect an individual from infection: "Whether you get medicine in your body, or condom, it is only God who protects. Whether I use condom or I don't use condom, it's only God."

\section{Fatalistic view of HIV infection}

Closely related to the concept of faith-based invulnerability is the belief in fatalism and predestination. To many of the women, those who will die from AIDS have already been predestined and consequently it made no sense taking preventive action if one's fate had long since been decided. A participant made clear her fatalistic conclusion: "If God says it will happen, so it will happen ... and will not die unless they reach the time God says they will die." Some extended it further by explaining that God has mapped up the cause of death for each individual and that it is futile to attempt to do otherwise. "If it's through an accident, so it will happen, if through malaria so it will happen, if through AIDS so be it." Another concluded that "you cannot change any of this on your own, it's only God."

\section{Power in the tongue}

A related observation, albeit contradictory to the concept of predestination, is the strong belief that those who will die from AIDS are those who think and perceive the possibility that they are at risk of contracting the infection. This idea of "positive thinking and confession" is a part of the cultural norm which suggests that evil befalls those who think and speak evil about their own situations. So in this sense silence is golden; do not think or talk about that evil and that evil will not happen to you. Consequently, from their viewpoint, avoiding or contracting AIDS is the battle of the 
mind rather than behavioral disposition, a point aptly stated by a participant: "It is your mind. It is what you say that is how your mind is and that is what you get." Another added: "Why should I stand a chance of catching it (HIV), even if I don't use condoms all the time. I can't wish that bad thing for myself." The belief leads to a situation where the women think one can reduce risk of infection by simply refusing to accept or deny the risk, which is a typical coping strategy to reduce dissonance.

\section{Customer is "king" in condom negotiation}

Sex work is fraught with risks. These may include physical violence from clients, intimidation from older or more experienced sex workers who may feel threatened by the arrival of younger women, bullying and sexual harassment by unscrupulous law enforcement agents, demands for sexual and other favors from brothel managers/landlords, and economic manipulation and outright exploitation by several other go-betweens. Within the context of a skewed power imbalance, most sex workers found a way of defending their nonuse of condoms. Most blamed clients, some of whom, they said, were not interested in using condoms. The women wholly absolved themselves and shifted responsibility to men. A woman described the conflicting decision-making process: "Because of money, maybe you don't have any money at your room that day and that person come want to give you N20,000 (about ten times the normal rate) and if he said that he will not use condom, and you look you don't have money, you will just have to collect that money." Another mentioned: "The thing there is that men might not agree to use condom because they said they are not enjoying it by using condom, then you being a woman you don't have money to eat. You will agree to do it like that without condom, so that you may even use it to get money to eat."

\section{Discussion}

The theory of cognitive dissonance has been used extensively in marketing to explain the choices people make and how people explain and justify purchasing decisions, mainly to avoid "buyer's remorse" following the purchase of expensive items. On the whole, most people want to convince themselves and hold on to the belief that they have made good choices. ${ }^{23}$

In this study, sex workers kept on emphasizing that in sex work the old adage holds true, ie, the customer is "king." As has been found in South Africa, ${ }^{24}$ where insistence upon condom use was responsible for client loss, nonpayment for services, and physical abuse in some cases, sex workers in our study maintained that, more often than not, the customer, backed by his money, dictated the terms of most sexual acts. While the powerlessness of sex workers is real, the women's reliance on blaming men put together with our previous findings, seem to suggest another example of shifting blame to reduce dissonance. Because of the perceived hopelessness of their situation, and to reduce worries and anxieties they would charge higher fees from clients rather than worry about AIDS which may or may not manifest in the future.

To reduce dissonance, most sex workers charged higher for sex without condoms, thereby reducing anxieties, perceiving that the transaction had high benefit and was worth the risk. Just like advertising is used to reduce dissonance, the efforts of some of the women who asked their clients to use condoms were often stymied by customers who enticed them with even more handsome financial offers in exchange for sex without condoms. The women narrated how they constantly faced the dilemma of choosing between economic survival and unsafe sex, and many were more concerned with economic survival than the possibility of contracting HIV.

We also explored some of the defensive coping mechanisms which make sex workers think they are not at risk of HIV infection. Defensive coping is a state in which a person repeatedly presents inaccurate "positive self-evaluation as a defense against underlying perceived threat." ${ }^{25}$ Defensive coping is often characterized by rationalization of "failures" and projection of blame and responsibility. ${ }^{25}$ There was considerable evidence of optimism bias. This is the mistaken belief that one's chances of experiencing a negative event are lower (or a positive event, higher) than that of one's peers. ${ }^{26}$ The optimism bias, in line with the theory of cognitive dissonance, is a typical psychological response to worry, threat, and anxiety arising from the apparent discrepancies between beliefs and behaviors.

Optimism bias is often amplified when the risky event is regarded as controllable and can be prevented through caution or effort. ${ }^{27}$ It could, as in this study, result in egocentric bias. This is the situation where people feel that they are unlikely to be susceptible to negative events. However, these same people do not assume that other individuals are equally non-susceptible. As a consequence, they perceive other individuals, but not themselves, as susceptible to negative events. Similarly they feel they are more susceptible to negative uncontrollable events. ${ }^{27,28}$ Many of the sex workers considered their risk of HIV infection lower than their peers who were not sex workers. 
Cognitive dissonance highlights three key strategies to reduce or minimize dissonance. These focus more on supportive beliefs that outweigh the dissonant behavior, reducing the importance of the conflicting belief, or changing the conflicting beliefs so that it is consistent with behavior. McMaster and $\mathrm{Lee}^{29}$ have reported how smokers employ these strategies to reduce dissonance. Smokers can rationalize supportive beliefs that may outweigh dissonance by believing that smoking is not as harmful as drinking alcohol. Smokers can also reduce the importance of the conflicting belief by ignoring or questioning the validity of evidence that links smoking and ill-health. Similarly smokers may change the conflicting belief by rating the effects of smoking as being less dangerous than nonsmokers do. ${ }^{29}$

In our study, many sex workers focused on supportive beliefs that outweighed dissonant behavior by believing strongly that sexual transmission was not the only route of transmission. Dissonance was reduced by knowing that HIV could be contracted in several other ways. Secondly, the importance of the conflicting belief, ie, engaging in unsafe sex, was reduced in importance by believing that condom use was not very important because one can get infected anyway if one is predestined to die from AIDS. Thirdly, dissonance was reduced by the fact that it was the client but not the sex worker herself who had the final say in condom use, and therefore condom use was an uncontrollable event.

It was found that sex workers assessed risk and balanced the potential risk with ineffective risk reduction and avoidance strategies. One of the puzzling findings in AIDS research has been the inconsistent relationship between perception of personal risk and engagement in unsafe sexual practices. ${ }^{30} \mathrm{In}$ order to ensure that there is congruence between what they believed and how they behaved, many sex workers in the study rationalized their behaviors and substantially played down the risks of HIV infection. This may be explained in line with the principle of balance theory. ${ }^{18}$ Consequently, many sex workers saw HIV/AIDS as a problem but chose to put forward several strategies, which they thought might lead to risk reduction or avoidance. Rather than considering themselves at a risk higher than average, there was evidence of risk-leveling by believing that "everybody is at risk."

Fatalism was also found to be a risk factor and a key hindrance towards safe behavioral practices. To many of the sex workers, the extent of their self-perceived risk might depend on faith in God, belief in predestination, and the power of positive thinking and positive confession. They felt more comfortable placing their trust in the protective power of God and whatever they perceived had been ordained for them by
God rather than in objective self-assessment of the risk of contracting HIV. Such fatalistic views concerning HIV/AIDS can reinforce the erroneous belief that contracting HIV is more a matter of fate than an outcome determined by one's sexual behavior. It reduces anxiety on the part of sex workers who think that whether or not one is infected is beyond their control and in so doing reduces dissonance.

Social and attitudinal research in many health behavior areas has shown that taking steps to initiate risk reduction behavior change requires personalization of risk. ${ }^{31}$ Therefore, one area of intervention might be activities which develop the accuracy of personal vulnerability and risk self-appraisal. However, enhancing risk sensitization among sex workers by helping them to gauge their personal vulnerability is particularly complex. This might lead to defensive coping. ${ }^{25}$ A direct confrontational approach could have potentially adverse consequences. Extensive emphasis on risk factors among persons with excessive risk behaviors may induce fear and psychological distress, which may in turn be a barrier to behaviour change by reinforcing denial, as can be seen from our study.

It appears from our research that focusing excessively on the risks associated with sex work may induce fear, which in turn may cause sex workers to ignore, deny, or refuse to seek out HIV-related information. This observation is consistent with the finding that stimulating the fear of AIDS or raising concerns about the disease leads to avoidance of any discussion related to AIDS. ${ }^{32,33}$ It might also lead to fatalism and reliance on God for protection. As noted by Kelly, ${ }^{31}$ there is probably an optimal level of vulnerability sensitization, in that with too little fear, people will not be motivated to change, but with too much fear, they may avoid or deny the threat.

HIV denial could even be exacerbated given the sex workers' judgment about HIV-positive people. Cognitive dissonance plays a role in many value judgments. In line with cognitive dissonance, this produces unrealistic optimism. This is related to "stereotypical" or "prototypical" judgment. ${ }^{34}$ Many of them tended to conclude that the risk of HIV infection does not apply to them but only to those who fit the negatively formed stereotypical image. Sex workers mentally disassociated themselves from HIV and held highly stigmatizing attitudes to persons living with HIV and AIDS.

On the surface, the hostile attitude to persons living with HIV and AIDs is surprising because some knew of colleagues who had died from AIDS. But they kept "balanced" by being hostile to persons living with HIV, and in so doing believed that it would not happen to them. In a sense by 
disassociating themselves from the disease, sex workers in some way blocked off the possibility of getting a disease they so despise. The high level of stigmatization held by sex workers for people living with HIV or AIDS may lead to low levels of disclosure and may limit their willingness to access regular HIV counseling, testing, and care.

Although the study provides data for understanding the nature and form of personal HIV risk assessment among sex workers, it has potential biases resulting from selection issues, so its results are not representative and therefore not generalizable to all sex workers in Nigeria. Again the study was limited to brothel-based sex workers and the findings may not be applicable to nonbrothel-based sex workers. Furthermore, in qualitative research, the data could be subject to multiple interpretations. The conclusions derived from the use of latent content analysis, which often leads to a higher level of abstraction in data interpretation, could be different if interpretation had been based solely on manifest analysis.

\section{Conclusion}

Many sex workers underestimate the risks associated with sexual risk-taking, particularly the risk of contracting HIV. Furthermore, sex workers selectively distorted information in order to minimize feelings of personal vulnerability and avoid confronting the urgent need to change behavior. Designing interventions that ensure that sex workers accurately understand their risks and are more prepared to reduce HIV-related risks is indeed a challenge for HIV program managers. This is often compounded by the fact that sex work is "survival sex" based on commercial transactions in which the feelings, demands, and interests of the customer often take precedence over those of the woman, even if there are apparent risks of contracting HIV. Sex work affords women important economic benefits, and programs need to address the benefits versus costs associated with behavior change because it is self-evident that it is much more difficult for condom use to be introduced by the weaker party in any power-imbalanced relationship.

At the extreme end of perceived invulnerability was a small group of sex workers who shared feelings of rejection and dejection, and often perceived themselves as powerless to change their conditions. It is known that positive evaluations of self-worth can enhance a person's ability to avoid risk-inherent sexual behaviours. ${ }^{31}$ Within a context of pervasive hopelessness and with very little reason for optimism of better times and personal advancement ahead, it may be very difficult for sex workers to act on standard risk reduction recommendations. ${ }^{35}$ At the moment, many interventions are unable to make any impact among sex workers because they focus only at the tail end of the behavior change continuum, ie, behavior change through condom use. While this may be effective among persons who may consider themselves at risk of infection, the goal of interventions may initially be focused as suggested by Kelly ${ }^{31}$ on assessing readiness for change and to determine what level of motivational and risk sensitization is needed in the early phase of HIV interventions among sex workers.

Because most of the sex workers did not consider themselves at risk of HIV infection, this must be of great concern to programmers in a country where HIV prevalence among sex workers has hovered around $30 \%$ in the last decade. It is necessary for programs to encourage sex workers to undertake accurate self-appraisal of risk. While knowledge of risky behavior does not necessarily translate to behavior change, ability to identify risky behaviors is a necessary precondition for behavior change.

\section{Acknowledgment}

The study upon which this paper is based was supported by the British Department for International Development and the United States Agency for International Development.

\section{Disclosure}

The authors report no conflicts of interest in this work.

\section{References}

1. Ilesanmi AO, Lewis I A. Adolescent prostitution. In: Status of adolescents and young adults in Nigeria. Ibadan, Nigeria: Center for Health Sciences Training, Research and Development; 1997.

2. Forbi JC, Onyemauwa N, Gyar SD, Oyeleye AO, Entonu P, Agwale SM High prevalence of hepatitis B virus among female sex workers in Nigeria. Rev Inst Med Trop Sao Paulo. 2008;50:219-221.

3. Federal Ministry of Health. A report of 1995/96 HIV sentinel serosurveillance in Nigeria. Abuja, Nigeria: National AIDS/STDs Control Program; 1997.

4. Federal Ministry of Health. HIV/STI integrated biological and behavioural surveillance survey 2007. Abuja, Nigeria: Federal Ministry of Health; 2007.

5. Federal Ministry of Health. 2010 national HIV seroprevalence sentinel survey among pregnant women attending antenatal clinics in Nigeria. Abuja, Nigeria: Department of Public Health; 2011.

6. Oladembe R, Adeniji GO, Omilaju I, Adebayo S, Somda Z, Fajemisin O. HIV modes of transmission in ogun state: an analysis of the distribution of new infections. Abuja, Nigeria: Enhancing Nigeria Response to HIV/ AIDS Project; 2010.

7. Baba-Manu A, Nwankwo E, Wende G, et al. HIV modes of transmission in Benue State: an analysis of the distribution of new infections. Abuja Nigeria: Enhancing Nigeria Response to HIV/AIDS Project; 2010.

8. World Bank. The AIDS epidemic. Geneva, Switzerland: The World Bank; 1997.

9. Williams ES. Women of courage: commercial sex workers mobilize for HIV/AIDS prevention in Nigeria. AIDS captions. 1994;1:19-22.

10. Ogun State University Teaching Hospital Research Team. A qualitative research on the sexual health needs of commercial sex workers in sabo, sagamu. Abeokuta, Nigeria: Ogun State University Teaching Hospital; 1999. 
11. Chiwen JO, Mohammed I. Human immunodeficiency virus Type I (HIV I) infection among female prostitutes in Borno State, Nigeria. East Afr Med J. 1989;66:752-756.

12. Chimaraoke IO. Constituting the unsafe: Nigerian sex workers' notion of unsafe conduct. Afr Stud Rev. 2007;50:29-49.

13. Imade G, Sagay A, Egah, et al. Prevalence of HIV and other sexually transmissible infections in relation to lemon or lime juice douching among female sex workers in Jos, Nigeria. Sexual Health. 2008;5: 55-60.

14. Oyefara JL. Food insecurity, HIV/AIDS pandemic and sexual behaviour of female commercial sex workers in Lagos metropolis, Nigeria. SAHARA J. 2007;4:626-635.

15. Messersmith LJ, Kane TT, Odebiyi AI, Adewuyi AA. Who's at risk? men's STD experience and condom use in southwest Nigeria. Stud Fam Plann. 2000;31:203-216.

16. Wallman S. Global threats, local options and personal risk: dimensions of migrant sex work in European cities. Health Risk Soc. 2001;3:75-87.

17. Festinger L. A theory of cognitive dissonance. Evaston, IL: Row, Peterson and Company; 1957.

18. Heider F. The psychology of interpersonal relations. New York, NY: Wiley; 1958.

19. Bauman LJ, Siegel KS. Persistence of risky sexual practices of gay and bisexual men in New York City. J Appl Soc Psychol. 1987;17:329-350.

20. Burnard P. A method of analyzing interview transcripts in qualitative research. Nurse Educ Today. 1991;11:461-466.

21. Graneheim UH, Lundman B. Qualitative content analyis in nursing research: concepts, procedures and measures to achieve trustworthiness. Nurse Educ Today. 2004;24:105-112.

22. Kondracki NL, Wellman NS, Amundson DR. Content analysis: review of methods and their application in nutrition education. J Nutr Educ Behav. 2002;34:224-230.

23. Harmon-Jones E, Mills J. Cognitive dissonance progress on a pivotal theory in social psychology. Washington, DC: Braun Brumfield Inc; 1999.
24. Karim AQ, Karim SSA, Soldan K, Zondi M. Reducing the risk of HIV infection among South African sex workers: socioeconomic and gender barriers. Am J Public Health. 1995;85:1521-1525.

25. Carpenito-Moyet LJ. Nursing diagnosis: application to clinical practice. 13th ed. Philadelphia, PA: Lippincott Williams \& Wilkins; 2009.

26. Weinstein ND. Unrealistic optimism about future life events. J Pers Soc Psychol. 1980;39:806-820.

27. Harris PR, Griffin DW, Murray S. Testing the limit of optimistic bias: event and person moderators in a multilevel framework. J Pers Soc Psychol. 2008;95:1225-1237.

28. Price PC, Pentecost HC, Voth RD. Perceived event frequency and the optimistic bias: evidence for a two-process model of personal risk judgment. J Exp Soc Psychol. 2002;38:242-252.

29. McMaster C, Lee C. Cognitive dissonance in tobacco smokers. Addict Behav. 1991;16:349-353.

30. Petty RE, Gleicher F, Jarvis WB. Persuasion theory and AIDS prevention. In: Pryor J, Reeder G, editors. The social psychology of HIV infection. Hillsdale, NJ: Lawrence Erlbaum Associates; 1993.

31. Kelly JA. Changing HIV risk behavior: practical strategies. New York, NY: The Guilford Press; 1995.

32. Friedman SR, Des Jarlais DC, Sotheran JL. AIDS health education for intravenous drug users. Health Educ Q. 1986;13;383-393.

33. Joseph JG, Montgomery SB, Emmons CA, et al. Perceived risk of AIDS: assessing the behavioural and psychosocial consequences in a cohort of gay men. J Appl Soc Psychol. 1987;17: 231-250.

34. Van der Pligt J, Otten W, Richard R, Van der Velde F. Perceived risk of AIDS: unrealistic optimism and self-protective action. In: Pryor J, Reeder G, editors. The social psychology of HIV infection. Hillsdale, NJ: Lawrence Erlbaum Associates; 1993.

35. Cochran SD, May VM. Women and AIDS-related concerns: roles for psychologists in helping the worried well. Am Psychol. 1989;44: 529-535.
HIV/AIDS - Research and Palliative Care

\section{Publish your work in this journal}

HIV/AIDS - Research and Palliative Care is an international, peerreviewed open-access journal focusing on advances in research in HIV, its clinical progression and management options including antiviral treatment, palliative care and public healthcare policies to control viral spread. The journal welcomes original research, basic science,

\section{Dovepress}

clinical \& epidemiological studies, reviews \& evaluations, expert opinion \& commentary, case reports \& extended reports. The manuscript management system is completely online and includes a very quick and fair peer-review system. Visit http://www.dovepress.com/ testimonials.php to read real quotes from published authors. 